\title{
Multilingual access \\ Language hegemony and the need for discoverability in multiple languages
}

t is widely accepted that English is the

current lingua franca, especially in the scientific community. ${ }^{1}$ With approximately 527 million native speakers globally, English ranks as the third most-spoken language (after Chinese and Hindu-Urdu), but there are also an estimated 1.5 billion English-language learners in the world. ${ }^{2,3}$

The preeminence of English reflects the political power of the English-speaking world, ${ }^{4}$ carrying privileges for those who can speak, write, and read in English, and disadvantages to those who cannot. This is also the case in scholarly communication. Linguist Nicholas Subtirelu identifies three privileges for native English speakers: 1) easier access to social, political, and educational institutions; 2) access to additional forms of capital; and 3) avoiding negative opinions of one's speech. ${ }^{5}$

For example, we were both born into families that speak American English at home, we were surrounded by English books and media growing up, and our entire education was in English. Even defining who counts as a "native" speaker can be refracted through other social identities. As college-educated white Americans, our English is never questioned, but the same is not true for many equally fluent people around the world.

A highly cited study in the European Journal of Epidemiology found that the variation of publication output between Organisation for Economic Co-operation and
Development nations could be explained by differences in research spending and English proficiency. ${ }^{6}$ And, although nonnative writers are often at a disadvantage and have spent significant time, effort, and money learning the language, they may still hold privileges when compared to other learners, because they had access to technologies (such as high-speed Internet), conversation partners, and media.

Subtirelu notes, "Thanks to the global dominance of English-speaking academia, 'international' is more or less a euphemism for journals published in English." " Academic librarians who support the broadest access to scholarship and research should acknowledge the hegemony of English and find ways both to problematize and destabilize that dominance, even through seemingly small steps.

This article is a call to action, outlining the limitations of machine translation, a suite of options for multilingual access, and specific actions that journals, scholars, and librarians can take. While the options we describe may seem piecemeal, grassroots, or even haphazard, we believe that

Kelly McElroy is student engagement and community outreach librarian, email: kelly.mcelroy@oregonstate. edu, and Laurie M. Bridges is instruction and outreach librarian, email: laurie.bridges@oregonstate.edu, at the Oregon State University Libraries

C 2018 Kelly McElroy and Laurie M. Bridges 
every action to address English-language dominance can contribute to broader lasting change.

\section{Google Translate is not enough}

To understand how cumbersome the process is, if you are a monolingual English speaker, we encourage you to find a research article about a specific topic in another language, then read and summarize it using Google Translate.

A 2014 study found Google Translate accurately translated key medical phrases just over half of the time, with African languages having the worst accuracy-only 10\% of Swahili phrases were correctly translated. ${ }^{8}$ If Google Translate is inadequate for discussing medical issues with patients, we question its capacity to capture the nuance of research findings.

A recent article in PLOS Biology is one of the few studies that explores the difficulty of using Google Scholar for researchers who do not know English. The authors searched for articles published in 2014 in the field of biodiversity conservation in 16 languages: 64.4\% were in English, $12.6 \%$ of those were in Spanish, 10.3\% in Portuguese, 6\% in simplified Chinese, and 3\% in French.

In addition, the authors found that articles written in other languages were often not found when searching in English, even when the article had an English title or abstract. The authors point out that scientists in the field may be less likely to know English, creating a gap between researchers and practitioners. As they note, "leaving this problem unresolved is untenable if we consider that areas experiencing a rapid loss of biodiversity and thus in the greatest need of information, education, and conservation practices are often places where English is not spoken widely."

\section{Approaches to multilingual access}

Multilingual access addresses language barriers to information access in numerous ways. ${ }^{10}$ For example, Archivaria, the journal of the Association of Canadian Archi- vists, invites articles in French or English, Canada's official languages. ${ }^{11}$ Because Canada is a bilingual country, there are common expectations and practices around translation, but the concrete examples still provide a model we can consider from the United States. Archivaria also models another common form of multilingual access: the translation of abstracts into more than one language. All abstracts in the journal are translated into the other official language, providing discoverability in both French and English. Even in countries without multiple official languages, journals may choose to provide Englishlanguage titles and abstracts to increase discoverability.

The practice of providing abstracts and titles in more than one language was recently encouraged in an editorial in the Lancet Global Health on behalf of the Healthcare Information for All Working Group on Multilingualism. ${ }^{12}$ Neil Pakenham-Walsh writes that journals should make at "least the abstract available in the main language or languages of the country in which the research was done. This requirement could be stipulated condition of publication on the basis of research ethics grounds, to be done by the authors themselves." ${ }^{13}$

In the case of intentionally multilingual journals like Archivaria, abstracts are always provided in multiple languages. Most, if not all, journal publishing platforms and institutional repository software have the capacity to include fields in multiple languages. When publishing in a typically monolingual journal, scholars can ask if a translated abstract can be included. While hardly a systematic solution, this is one small way that authors can increase multilingual access to their work.

Librarians can also do this for their own research. For example, for an article that we published in In the Library with the Lead Pipe about our experience leading study abroad courses, we wanted to provide the abstract not only in English, but in the languages spoken in the cities we had visited 
with our students. The journal's editors included the Catalan, Italian, and Spanish translations we provided, which were also picked up when the article was indexed by the database Library, Information Science, and Technology Abstracts. ${ }^{14}$ While an interested Italian-only speaker would still need to find a way to translate the full-text, the abstract increases discoverability of the research overall.

Translated abstracts can offer increased access on both sides of the English language divide. As the authors of the aforementioned PLOS Biology article suggest, those who assume that all scholarship is published in English cut themselves off from research that is not published in English. ${ }^{15}$ As mentioned earlier, in their study, more than a third of the scientific documents on biodiversity searchable through Google Scholar were in languages other than English. Overemphasizing the ubiquity of English in scholarship cuts out the potential for communication across languages. Mohsen Rezaeian invites scholars to work with native English speakers to get themselves greater access to published research and to publishing opportunities, and this practice can also give monolingual English speakers greater access to research produced in other languages. ${ }^{16}$

\section{Actions toward multilingual access}

The dominance of English in scholarly publishing is unlikely to change quickly. However, there are actions that English-speaking scholars and librarians can take, as individuals and within organizations, to bridge access to information across languages. While it is appealing to imagine how to assign responsibility for translations to journals or granting agencies, a pragmatic approach recognizes that there are opportunities throughout the scholarly publishing process for advocacy and solidarity.

Many universities have funds for open access article publication charges. ${ }^{17}$ Universities should similarly consider setting aside funds to pay for translations into other languages. Guidelines for disbursing those funds can invite researchers to consider the languages spoken in their field locations, among other criteria. Universities where translation programs exist can set up opportunities for experiential learning, collaborating with the research office or library.

English-language journals and conferences can also explicitly encourage collaboration between authors who write in different languages, for example by including this in calls for participation (CFP), and by purposefully sharing translated CFPs to communities where English is not the primary language. For example, the CFP and much of the website for Digital Humanities 2018, held in Mexico, was translated fully into Spanish, and included an explicit invitation to submit in either of those languages, as well as others where an adequate group of reviewers was available. ${ }^{18}$

Rezaeian suggests that medical journals regularly feature "well-conducted research that highlights relevant local and national health problems in the developing world."19 Journals could similarly implement practices to publish articles from authors outside of English-majority countries. Author guidelines can explicitly invite titles and abstracts in multiple languages. Policies for peer review can also provide guidelines for reviewing articles by less fluent writers, to reduce bias based on style rather than content. Finally, editorial boards can consider their capacity for publishing submissions in multiple languages.

Individual scholars can include translated abstracts for their own work and seek out opportunities to collaborate across language. Researchers can include translation as part of their dissemination plan as they write grants. They can also request translations of important works, by advocating to journals, colleagues, or professional associations.

Libraries can review their IRs for studies that have been conducted on behalf of their universities in locations where English is not spoken widely, and pursue funding to translate the titles and abstracts, and even the articles, into local languages.

Librarians can do all of the above in their capacities as researchers and contributors to 
journals. In addition, they can help spread the word, adding documentation to publications and repositories for multilingual abstracts, keywords, and full-text, encouraging graduate students and faculty to consider whether speakers of other languages would benefit from access to their research, and addressing language and discoverability in instruction.

\section{Notes}

1. Christopher Baethge, "The Languages of Medicine," trans. Ethan Taub, Deutsches Ärzteblatt 105, no. 3 (2008): 37-40.

2. Rick Noack and Lazaro Gamio, "The World's Languages, in 7 Maps and Charts," The Washington Post, April 23, 2015, https://www.washingtonpost.com/news /worldviews/wp/2015/04/23/the-worlds -languages-in-7-maps-and-charts/.

3. Ulrich Ammon, "Global English and the Non-Native Speaker: Overcoming Disadvantage," in Language in the 21st Century, ed. Humphrey Tonkin and Timothy Reagan (Amsterdam: John Benjamins Publishing Company, 2003), 23-34.

4. Sik Hung Ng and Fei Deng, "Language and Power," Oxford Research Encyclopedia of Communication, August 22, 2017, http:// communication.oxfordre.com/view/10.1093 /acrefore/9780190228613.001.0001/acrefore -9780190228613-e-436.

5. Nicholas Subtirelu, "Language Privilege: What It Is and Why It Matters," Linguistic Pulse (blog), June 26, 2013, https:// linguisticpulse.com/2013/06/26/language -privilege-what-it-is-and-why-it-matters/.

6. Jonathan P. Man et al., "Why Do Some Countries Publish More Than Others? An International Comparison of Research Funding, English Proficiency and Publication Output in Highly Ranked General Medical Journals," European Journal of Epidemiology 19, no. 8 (August 1, 2004): 811-17, https://doi. org/10.1023/B:EJEP.0000036571.00320.b8.

7. Nicholas Subtirelu, "Denying Language Privilege in Academic Publishing," Linguistic Pulse (blog), March 28, 2016, https:// linguisticpulse.com/2016/03/28/denying -language-privilege-in-academic-publishing/.
8. Sumant Patil and Patrick Davies, "Use of Google Translate in Medical Communication: Evaluation of Accuracy," BMJ 349 (December 15, 2014): g7392, https://doi. org/10.1136/bmj.g7392.

9. Tatsuya Amano, Juan P. González-Varo, and William J. Sutherland, "Languages Are Still a Major Barrier to Global Science," PLOS Biology 14, no. 12 (December 29, 2016): e2000933, https://doi.org/10.1371/journal. pbio. 2000933.

10. Jiangping Chen, Multilingual Access and Services for Digital Collections (Libraries Unlimited, 2016), http://public.eblib.com /choice/publicfullrecord.aspx?p=4332329.

11. "Submissions to Archivaria," Archivaria: The Journal of the Association of Canadian Archivists, accessed October 2, 2018, https://archivaria.ca/index.php/archivaria/about/submissions\#authorGuidelines.

12. Neil Pakenham-Walsh, "Improving the Availability of Health Research in Languages Other than English," The Lancet Global Health, September 11, 2018, https:// doi.org/10.1016/S2214-109X(18)30384-X.

13. Pakenham-Walsh.

14. Kelly McElroy and Laurie M. Bridges, "Librarians Leading Short-Term Study Abroad," In the Library with the Lead Pipe, June 2017.

15. Amano, González-Varo, and Sutherland, "Languages Are Still a Major Barrier to Global Science."

16. Mohsen Rezaeian, "How to Write and Publish a Scientific Manuscript in English: Introducing Some Practical Guidelines for Non-English Speaking Scholars," Journal of Human Health 1, no. 3 (2015): 61-62.

17. Mohsen Rezaeian, "Disadvantages of Publishing Biomedical Research Articles in English for Non-Native Speakers of English," Epidemiology and Health 37 (May 1, 2015): 104, https://doi.org/10.4178/epih/e2015021.

18. Digital Humanities 2018, "Convocatoria-DH 2018,” accessed November 2, 2018, https://dh2018.adho.org/cfp/.

19. Rezaeian, "Disadvantages of Publishing Biomedical Research Articles in English for Non-Native Speakers of English." $\boldsymbol{n}$ 